could be completed by either full-time or part-time study combined with practical experience. The early courses for the diploma in mining followed a similar pattern, as did the degree courses instituted in 1913 under F. E. Armstrong (professor of mining, 1913-21). Since then the necessary practical experience has been gained largely by vacation work. The Department of Glass Technology was instituted as the result of experience gained during the First World War. In October 1914 the University set up a Scientific Advisory Committee with W. E. S. Turner (professor of glass technology, 1920-45), then lecturer in physical chemistry, as its secretary. Turner soon realized the need for the application of scientific methods to the manufacture of glass, and a full-time course for a diploma in glass technology was established in 1916, and a degree course in 1919. Fuel technology, which had been unequally yoked with applied chemistry, was made a separate chair in 1920 (R. V. Wheeler, professor of fuel technology, 1920-39) and degree and diploma courses instituted in 1921 .

The growth of the medical faculty between 1905 and 1945 owed much to the pioneer work of earlier teachers in the Medical School. Arthur Hall (professor of physiology, 1897-98, of pathology, 18991906, and of medicine, 1915-31) joined the Medical School as an assistant demonstrator in physiology in 1889 and strove successfully to establish full-time teaching departments in the subjects involving laboratory work. His work on behalf of the school was helped by Christopher Addison (Viscount Addison of Stallingborough, first Arthur Jackson professor of anatomy, 1897-1901). J. B. Leathes (professor of physiology, 1914-33) reorganized the courses, and did much to effect a revolution in the linking of laboratory work with clinical teaching not only in Sheffield but also throughout the country. The first full-time clinical chair was established in 1920 when Edward Mellanby was appointed professor of pharmacology, and with the chair was associated an appointment as physician at the Sheffield Royal Infirmary. When H. W. Florey was appointed to the chair of pathology in 1932, J. W. Edington became the first full-time professor of bacteriology, after having been for more than ten years responsible for both departments. A full-time professor of dental surgery (G. L. Roberts) was appointed in 1935 and a chair of biochemistry (H. A. Krebs) created in 1945. Since 1945, clinical chairs have been instituted in medicine, surgery, child health, obstetrics and gynaecology and social medicine.

The expansion in the range of studies offered at the University was accompanied by an increase in the numbər of students and a corresponding demand for increased teaching and residential accommodation. The natural expansion in buildings was, however, checked by the First World War and the subsequent depression. Extensions to the technological departments were completed in 1913 ; but further expansion had to wait until after 1930. Then, under the direction of A. W. Pickard-Cambridge (vice-chancellor, 1930 38) a new wing for the departments of pure science and extensions to the Departments of Mining and of Metallurgy were completed. In 1939 the Department of Glass Technology moved into its new building for which funds had been raised by the glass industry. The second World War interrupted the building programme. During the War, under the leadership of Sir Irvine Masson (vice-chancellor, 1939-52), the University had made notable contributions to the war effort both in research and in production. As soon as the War ended, plans were drawn up to serve the increased number of students which the University was called upon to train. Extensions to the Department of Mining were opened in 1953, and a large new building to provide expanded facilities in teaching and research in the Departments of Civil, Mechanical and Electrical Engineering was opened by the Minister of Defence in April this year. Postgraduate schools in physical metallurgy were opened in 1950, in applied mechanics in 1951 and in mining in 1952. This expansion in applied science naturally requires expanded provision for teaching and research in the fundamental pure sciences. A new building for chemistry was opened in 1954, and the accommodation vacated has been altered for the use of departments in the faculties of pure science and of medicine. The necessary sites in the neighbourhood of Western Bank have been acquired for a complete University Quarter, and plans for new buildings for the library, arts, law, physics, the Medical School and administration have been drawn up.

All this expansion has provided, and is providing, domestic problems of considerable magnitude. The public spirit of Sheffield ladies was soon stirred to arrange halls of residence for women students. Soon after 1930 three of these small halls were united in one larger hall. At about the same time the first hall of residence for men was built and a Students Union provided by the generosity of J. G. Graves. Additional halls of residence for men were opened in 1947 and in 1952. A full-time warden of lodging was appointed in 1947, and the student health service set up in 1948 now has three full-time medical officers. Extensions to the halls of residence are planned, as are new buildings for the Students Union, refectories and a staff house. A new playing field near the University has been opened, and the site for another acquired. The material resources planned are impressive; their use will depend on character and ideals.

Universities exist to extend knowledge, to conserve knowledge and to hand on knowledge. Sheffield can claim that it has performed all these functions in the past and can, with some degree of confidence, hope to continue to perform them in the future.

\section{COLOUR SPECIFICATION}

\section{POSSIBLE REVISION OF THE C.I.E. SYSTEM}

A LTHOUGH the principles of colour-matching $A_{\text {with mixtures of three coloured lights were }}$ worked out in the latter half of the nineteenth century -notably by Helmholtz, Maxwell, König and Abney -it was not until 1931 that an agreed system of colour specification based on these principles was adopted. The essential preliminary was an adequate knowledge of the colour-matching properties of the average colour-normal eye. During 1927-30 excellent investigations of colour-matching by Guild and Wright respectively, using different groups of subjects, gave closely concordant results for a vital part of the information required, namely, the quantities, two positive and one negative, of the three component lights in a mixture to match an unspecified amount of each of the spectral colours. (The negative sign means that in the match the component light has to be mixed with the spectral stimulus.) The Commission Internationale de l'Éclairage had 
earlier adopted a standard visibility function $V_{\lambda}$ defining the reciprocal intensities in energy units of spectral stimuli having the same brightness or luminosity for the average eye. A combination of the mean Guild-Wright data with the standard visibility function $V_{\lambda}$ enabled the Commission to adopt, in 1931, a complete quantitative basis for colour specification, that is to say, a tabulation of the colour-matching functions or quantities of three component lights in a mixture to match unit energy intensity of each of the spectral colours. The component lights for which the Commission agreed the basic data were three spectral stimuli $(700 \cdot 0$, $546 \cdot 1$ and $435.8 \mathrm{mu}$ ), but for colour specification it was decided that the data should be transformed to a different set of mixture components, the so-called C.I.E. reference stimuli. The C.I.E. reference stimuli coincide with no actual physical stimuli-their relation to such stimuli is something akin to that between a virtual and a real image in geometrical optics-but this unreality is more than compensated for by the practical advantage of leading to positive colour co-ordinates for all real colours. The C.I.E. system is to-day the one fundamental system of colour specification in all branches of colour technology.

In reviewing the recent discussion by the Physical Society's Colour Group on April 27, it is first of all necessary to emphasize that no grave errors or shortcomings of the existing system have been brought to light, and those who have accepted and used it need not fear that their confidence has been misplaced. But there have been questionings which touch the underlying principles, the experimental data and the choice of reference stimuli. Work by Blottiau (1947) and Trezona (1953-54) suggests that the additive law of colour-matching, as applied to the measurements of a particular subject, is only approximately true. Again, while an indirect determination of the colour-matching functions by way of a $V_{\lambda}$ function may give correct results, it would appear preferable to use a direct method not involving heterochromatie photometry. As it turns out, doubts about the $V_{\lambda}$ data incorporated in the C.I.E. system initiated the move towards a revision. There is evidence that at short wave-lengths the values are too low. Considerable attention has been given to the additivity of brightness in heterochromatic photometry. This issue-quite distinct from the additive law in full colour-matching already referred to-would have no bearing on colour specification by the trichromatic method but for the fact that $V_{\lambda}$ data were used in setting up the present C.I.E. system.

It may be said that any significant defect in the basic data of the C.I.E. system would have shown itself in use before now. Only one serious claim has been made that in a technological application the C.I.E. system gives demonstrably incorrect predictions about colour matches. This fact must not be rated too high. Opportunities for clear-cut tests are not common and, because of the considerable individual differences in colour-matching, any discrepancy between the results of an actual observer and the computed result for the C.I.E. standard observer is likely to be laid at the door of the former. In one group of applications it would appear that the C.I.E. data cannot be giving quite the correct answers. This is when colour-matching of patches subtending considerably more than $2^{\circ}$ at the eye are concerned. The standard data refer specifically to a $2^{\circ}$ field, and it is known that field-size is a significant factor. Obviously, if only one set of colour-matching functions is to be standardized, it cannot be completely satisfactory for all practical field-sizes. But the best choice of field-size or the best compromise is not easy to determine.

The changes proposed in the C.I.E. reference stimuli have been mainly directed towards incorporating in the C.I.E. system additional information about colour perception. Every colour is characterized by three numbers - the unit co-ordinates $x, y, z$, of sum unity-and it is customary to represent the colour by a point in a rectangular $(x, y)$ plot. Experiments on colour discrimination show that in the C.I.E. $(x, y)$ diagram the distance apart of two points corresponding to stimuli equally bright but just perceptibly different in colour varies very widely in different colour regions. No transformation to new reference stimuli would give a perfect 'uniform chromaticity' diagram, but a considerable improvement over the C.I.E. diagram is possible. Other properties of colour perception emerge when we are concerned with the colour relations of pigmented surfaces viewed, under a suitable illumination, on a 'white' background. The representation of these properties is simpler with some choices of reference stimuli than with others. At the Physical Society's Colour Group meeting, Dr. R. W. G. Hunt urged the merits of a uniform chromaticity diagram due to MacAdam, while Mr. R. G. Horner favoured a more radical change in the method of plotting colour co-ordinates, adapted to represent surface colours.

The new experimental material which the Commission will have considered in discussing revision of its system in June includes studies of the $V_{\lambda}$ function in the blue end of the spectrum made respectively at the National Bureau of Standards, Washington, D.C., by Ishak and Teele, and at the National Physical Laboratory, Teddington, by Burch and Stiles, and a direct determination (that is, not involving the $V_{\lambda}$ function) of the colour-matching functions for $2^{\circ}$ and $10^{\circ}$ matching fields with spectral stimuli as the mixture lights. For the latter work, also being carried out at Teddington, the results for an initial group of ten subjects are now available. The new results for the $2^{\circ}$ field show certain interesting, if minor, deviations from the present C.I.E. values, deviations which are not attributable to the use of an inappropriate $V_{\lambda}$ function in the derivation of the C.I.E. system nor to differences of average eye pigmentation of the various groups of subjects concerned. These are additional to some deviations in the blue end of the spectrum which could spring from the factors mentioned. A difference in the conditions of the new work at the National Physical Laboratory as compared with that of Guild and Wright is the use of a 'blue' mixture light of shorter effective wave-length-about $445 \mathrm{m \mu}$ instead of $460 \mathrm{~m} \mu$. This should be immaterial, if the additive law for complete colour-matching is strictly true. A direct test of the effect on the unit co-ordinates of ehanging the 'blue' mixture stimulus from 460 to $445 \mathrm{~m} \mu$ had already been made for his own eye by Prof. W. D. Wright using his own spectral primary colorimeter, and the results, described at the Colour Group meeting, confirm the implication that the colour-matching functions may not be completely independent of the mixture colours used in their determination*. The results of similar comparisons being made at the National Physical Laboratory will be available shortly. The whole question of indivi- 
dual obedience to the additive law of colour-matching is of the first importance in visual theory. The bearing on colour specification in the C.I.E. system is of a different kind, and the practical outcome is perhaps less disturbing than might at first appear. If, as seems probable, additivity ambiguities are of no higher order of magnitude than individual differences in colour-matching properties and differences arising from the wide range of practical conditions of colour observation, the extra load on a 'standard observer', who must represent a compromise over all these variations, may not be great. But the problem of the best compromise is changed, and until we have a clearer picture of the additivity difficulties we would be ill-advised to alter the present system. This is so, even though on some points-such as the values of the colour-matching functions in the extreme blue, which are shown by all the new work to be too low in the C.I.E. system-some improvement would be possible now. For colour technology, a change in the C.I.E. system means an upheavalcomputations of new tables, adjustments of all kinds of colour specifications, modification of physical colorimeters, etc. - and it would be unthinkable to make an interim change now with the possibility of a further change a year or two later.

* Note added in proof. Prof. Wright has made additional measurements which avoid an uncertain interpolation previously involved. He now finds virtually no difference between the unit co-ordinates of the spectral colours obtained by the use of 'blue' primaries 445 and $460 \mathrm{~m} \mu$, respectively. The National Physical Laboratory comparisons, since available, also show only slight differences in the unit coordinates, although there appears to be a small change in the 'blue' colour-matching function.

W. S. STILES

\section{OBITUARIES}

\section{Dr. R. N. Salaman, F.R.S.}

Is Redeliffe Nathan Salaman, whose death occurred on June 12, aged eighty, the world has lost one of the grand old men of science. He was one of the very few remaining representatives of a world of learning that had not known the spectre of modern specialization, a world where the boundaries between on $\Theta$ science and another were scarcely recognized and even those between science and the humanities were comfortably bridged. Dr. Salaman's whole life and work illustrated this.

Born in September 1874, he attended St. Paul's School and became a scholar of Trinity Hall, Cambridge, where, though he was for some unaccountable reason never a Fellow, he was a familiar figure in the combination room for many long years. He began his scientific career in medicine, at the London Hospital, and in 1901 was made director of the Pathology Institute there. But this was the time when the spectacular rediscovery of the Mendelian laws of heredity had given birth to the new science of genetics; Salaman was one of the first in Great Britain to become interested in Mendelism and soon joined William Bateson's original group of British geneticists.

It was characteristic of him that his interest in the Mendelian laws embraced both their direct implication in relation to studies of the origin and relationships of racial groups in man and their indirect use in the improvement of one of man's chief food crops, the potato. In both these fields he published some of the first scientific studies; he was made director of the Potato Virus Research Station at Cambridge on its foundation, and in his work there was the first to make use of a wild relative of the domestic potato, since recognized as the Mexican species Solanum demissum or a derivative, in order to introduce resistance to potato blight, Phytophthora infestans, into cultivated potatoes. To this day $S$. demissum remains one of the main sources of resistant genes.

Salaman it was who in 1930 recognized the dawn of a new epoch in potato breeding with the Russian discovery of a whole polyploid series of relatives of the potato-some wild, some cultivated-growing in the Andes in South America; he took an active interest in the expedition sent by the British Commonwealth to collect these potatoes and in the foundation of the Commonwealth Potato Collection and the Potato Research Station at Cambridge which resulted from the expedition. Characteristically again, Salaman's imagination was fired by these potatoes just as much for their anthropological as for their genetical and agricultural significance; indeed, his book on the subject, entitled the "History and Social Influence of the Potato", is cited as much by historians and anthropologists as it is by geneticists or plant breeders; for these latter Salaman's researches have thrown light on the origin of the cultivated potato, its early introduction into Europe and its relationship to other, more primitive, potato species. For all readers it serves as an illustration of how an eminent scientist may yet be a master of English literary style-a fact also appreciated by anyone who has attended one of the many lectures that Salaman was so often called upon to deliver.

In 1935 Salaman was elected to fellowship of the Royal Society. In spite of his multifarious activities in the fields of medical pathology, plant genetics, phytopathology and anthropology, he was one of those busy people who always find time for something else. Living as a country gentleman at Barley in Hertfordshire, he was surrounded by a large family, took an active part in local good works, and in the critical years of the Nazi and other persecutions made an energetic contribution to the activities of the Council for the Protection of Science and Learning. In London he was a familiar figure in the rooms of the Athenæum, and there are few men of the present day who can be said to have led a more varied and constructive life, embracing so wide a field of diverse interests and activities.

P. S. Hudson

\section{Prof. D. B. Blacklock, C.M.G.}

THE death occurred on June 10 of Donald Breadalbane Blacklock, emeritus professor of tropical hygiene in the University of Liverpool. $\mathrm{He}$ was born on January 7, 1879, at Oban, Argyllshire, and was educated at Fettes College and at the University of Edinburgh, where, after a distinguished career both in studies and in sport (he played cricket for the University and rugby for Edinburgh Wanderers), he graduated M.B., Ch.B. in 1902, proceeding to the degree of M.D. in 1909. In 1911 he was appointed to the Runcorn research laboratory of the Liverpool School of Tropical Medicine, where he worked, first as research assistant and later as director, until 1914, when he was appointed lecturer in parasitology to the Liverpool School. 